\title{
ELECTROCHEMICAL PREPARATION AND CHARACTERISTICS OF PLATINUM ELECTRODE SURFACES WITH PREFERRED ORIENTATIONS
}

\author{
R.M. CERVIÑO, W.E. TRIACA and A.J. ARVIA
}

Instituto de Investigaciones Fisicoqumicas Teóricas y Aplicadas. INIFTA. Casilla de Correo 16, Suc. 4. 1900 La Plala (Argentina)

(Received 21st February 1984; in revised form 24 August 1984)

\section{ABSTRACT}

A new electrochemical procedure to obtain platinum electrode surfaces with preferred orientations from bulk polycrystalline platinum is presented. The procedure involves the application of repetitive potential sweeps at high frequencies to a polycrystalline platinum electrode under carefully selected potential perturbation conditions. The electrochemical response of the surface structures achieved after the treatment approach closely those repor:-d in the literature for determined types of platinum single crystal faces.

\section{INTRODUCTION}

Monooriented metal surfaces are obtained from a properly cut single crystal [1-4], from thin Jayer metal deposition on an inert substrate [5,6], and from the metal surface reconstruction promoted by the interaction of either an ion or an electron beam with the crystal surface [7,8]. Recently, reconstruction of noble metal surfaces was achieved by applying repetitive potential perturbations of preselected characteristics. Thus, the application of repetitive square wave potential sweeps covering the oxide multilayer electroformation and electroreduction pitiential range at different-frequencies yields a metal surface which. in the case of platinum [9], exhibits a preferential orientation of grains and for gold, probably approaches the equilibrium polycrystalline metal surface struc ure [10]. When the procedure involves the application of a repetitive triangular potential sweep to a polycrystalline platinum electrode in the potential range of $\mathrm{H}$ - and O-adatom electroadsorption/ electrodesorption at suitable potential sweep rates and switching potentials, changes in its electrochemical response in the direction of monooriented platinum electrode surfaces are observed [11]. The development of this simple technique offers for the first time the possibility of obtaining electiochemically solid electrodes with a relatively well-defined surface structure.

Obviously, the development of electrochemical techniques to manage the elec- 
trode surface structure is of the utmost importance for the reliable study of the electrode processes at solid electrodes, but, on the other hand, it also shows that data obtained with different relaxation techniques must be handled carefully because of the simultaneous modification of the electride surface structure throughout the duration of the experiment. Examples of the latter are most of the voltammetric results on noble metal electrodes in the p:tential range of $\mathbf{H}$ - and $\mathrm{O}$-adatom electroadsorption/electrodesorption [12,13].

The present paper refers to the electrocherrical preparation of platinum electrode surfaces with preferred orientations from $F$ ) iycrystalline platinum. Depending on the preparation procedure, two types of electrode surfaces are obtained. The voltammogram of the first type of electroce surface in the $\mathrm{H}$ - and O-adatom electroadsorption/electrodesorption potential range approaches closely that of the platinum (100) single crystal surface, while for șe second type of electrode suriace it is similar to that of a platinum (111) single $c_{-}$-stal surface after it has been cycled a few times through the anodic oxide region at a low potential sweep rate. The electrochemical characteristics and stability of the two types of electrode surfaces as well as the influence of the different param:tcrs which pertain to the developed technique are considered.

\section{EXPERIMENTAL}

Runs were made with commercially available polycrystalline platinum (Johnson Matthey Co.) working electrodes, either wire or plate shape, of ca. $0.15 \mathrm{~cm}^{2}$ geometric area. The working electrodes were subjected to a pretreatment which comprised the following successive steps: (i) immersion in hot aqua regia for about 2 min; (ii) repetitive rinsing in triply distilled water; (iii) immersion in a solution similar to that used i.d the electroly'sis ceil; (iv) application of an asymmetric triangular pote:stial sw sep $\left(v_{2}=200 \mathrm{~V} / \mathrm{s} ; v_{*}=0.1 \mathrm{~V} / \mathrm{s}\right)$ between 0.04 and $1.50 \mathrm{~V}$ for approximately $10 \mathrm{~min}$. The latter stage froduces a slight electropolishing of the metal surface which exhibits a very reproducible electrochemical behaviour. The potential of the working electrode was measured against a hydrogen reference electrode in the same acid electrolyte solution. A large-area platinum counter-elecirode concentrically surrounding the working electrode (ca. $50 \mathrm{~cm}^{2}$ ) was used. The electrodes were placed in an electrochemical cell designed for a low resistance.

Runs were made at $25^{\circ} \mathrm{C}$ in the following electrolyte solutions: (i) $1 \mathrm{M} \mathrm{H}_{2} \mathrm{SO}_{4}$; (ii) $1 \mathrm{M} \mathrm{H}_{3} \mathrm{PO}_{4}$; (ii) $5 \times 10^{-2} \mathrm{M} \mathrm{HClO}_{4}$. The electrolyte jolutions were preparred from a.r. grade chemicals and triply distilled water free ef organic impurities. The platinum electrode surfaces with preferred orientations wie obtained by subiecting the polycrystalline platinum to repetitive iriang ular poiential sweeps (RTPS) between the $E_{1}$ and $E_{\mathrm{u}}$ switching potentials at th = potential sweep rate $v$ during the time $t$. Values of $E_{1}, E_{u}, v$ and $t$ were idjusted according to the purpose of each run. The shape of the tri ingular signal was increasingly distorted according to $v$ and the shift fiom linearity at $\left(E_{\mathrm{i}}+E_{\mathrm{u}}\right) / 2$ was ca. $10 \%$ at $10000 \mathrm{~V} / \mathrm{s}$. 


\section{RESULTS}

Development of platinum electrode surfaces with a high contribution of (100)-like sites

When the switching potential values of the RTPS are fixed at $E_{1}=0.04 \mathrm{~V}$ and $E_{\mathrm{u}}=1.50 \mathrm{~V}$, the main electrochemical reactions taking place at the platinum electrode are those related to the $\mathrm{H}$ - and $\mathrm{O}$-adatom electroadsorption and electrodesorption with a decriasing participation of ageing effects as the frequency $(f)$ of the triangular potential sweep increases.

A comparison of the conventional stabilized voltammogram for polycrystalline platinum run at $0.1 \mathrm{~V} / \mathrm{s}$ with that obtained under the same conditions after the electrode is subjecticd to RTPS at a relatively low frequency $(v=100 \mathrm{~V} / \mathrm{s}$ or $f=0.034 \mathrm{kHz}$ ) for $20 \mathrm{~min}$ (Fig. 1) shows no remarkable changes in the voltammogram shape except for a slight variation in the distribution of the broad current peaks associated with the O-electroadsorption process. The height ratio of the H-adatom desorption current peaks (peaks la and IIa) remains practically constant. Thus, the polycrystalline platinum surface characteristics are maintained. In contrast, a considerable increase in the electrode active area, as measured through the corresponding electroreduction charge of the O-monolayer, is observed. In this case,

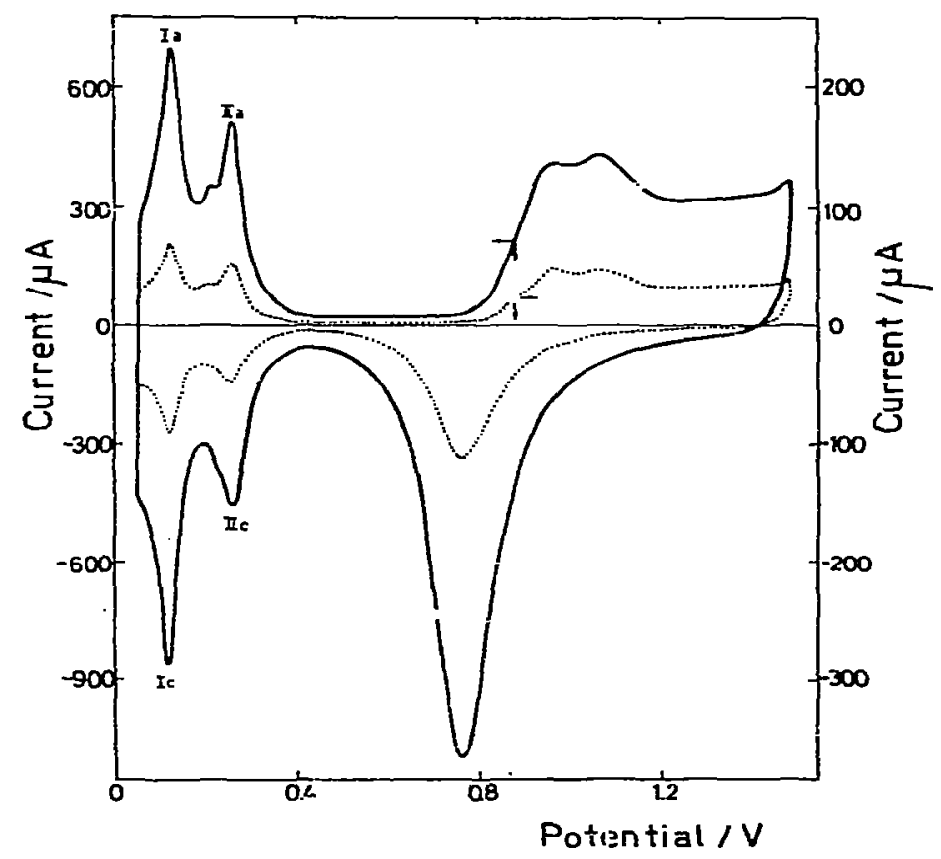

Fig. 1. Stabilized voitummogı ams (third cycle) run at $0.1 \mathrm{~V} / \mathrm{s}$ in $1 \mathrm{M} \mathrm{H}_{2} \mathrm{SO}_{4}$ at $25^{\circ} \mathrm{C}$. (一 -) After 20 min of RTPS at $100 \mathrm{~V} / \mathrm{s}$ between 0.04 and $1.50 \mathrm{~V} ;(\cdots)$ untreated polycrystailine platinum eiectrode. 
the O-electrodesorption charge ratio, $R$, is about 13 . This means that under the above-mentioned conditions the main effect of the RTPS treatment is to produce an increase in the active surface area. However, when the above-mentioned potential perturbation conditions last for $2 \mathrm{~h}$, the charge increase, $R \simeq 20$, is al:o accompanied by an increase in the peak IIa to peak Ia height ratio, which suggests a relative increase in the contribution of (100)-like sites to the overall polycrystalline electrode response.

When the frequency at the RTPS is increased by one order of magnitude $(f=0.34 \mathrm{kHz})$, after $t=2 \mathrm{~h}$, the voltammogram run immediately afterwards at $v=0.1 \mathrm{~V} / \mathrm{s}$ (Fig. 2) tends, particularly in the $\mathrm{H}$-adaiom potential range, towards that depicted in the literature [3,14-18] as the electrochemical response of the platinum (100) single crystal surface, i.e. peak 11 , at ca. $0.25 \mathrm{~V}$, renders the greatest current contribution at the expense of peak la. Likewise, a relative increase of the first broad current peak related to the O-electrcadsorption is noticed. Furthermore, in this case, the $O$ electrodesorption current peak potential lies at a value slightly more positive than that found in the conventional voliammugrami for polycrystalline platinum in the absence of the electrochemical treatment, The RTPS at $1000 \mathrm{~V} / \mathrm{s}$, besides changing the shape of the voltammo,ram, also produces an appreciable charge increase, but in this case to attain $P R$ value close to 6 a continucus $2 \mathrm{~h}$ i: $=$ atment should be applied to the polycrystalline electrode.

As the frequency of the R'TPS is raised $\leq 00.68 \mathrm{kHz}$ for a constant $t$ value the trend to approach the electrochemical characteristics of the (100) singie crystal surface is more evident and the increase in the electrode active area is gradually

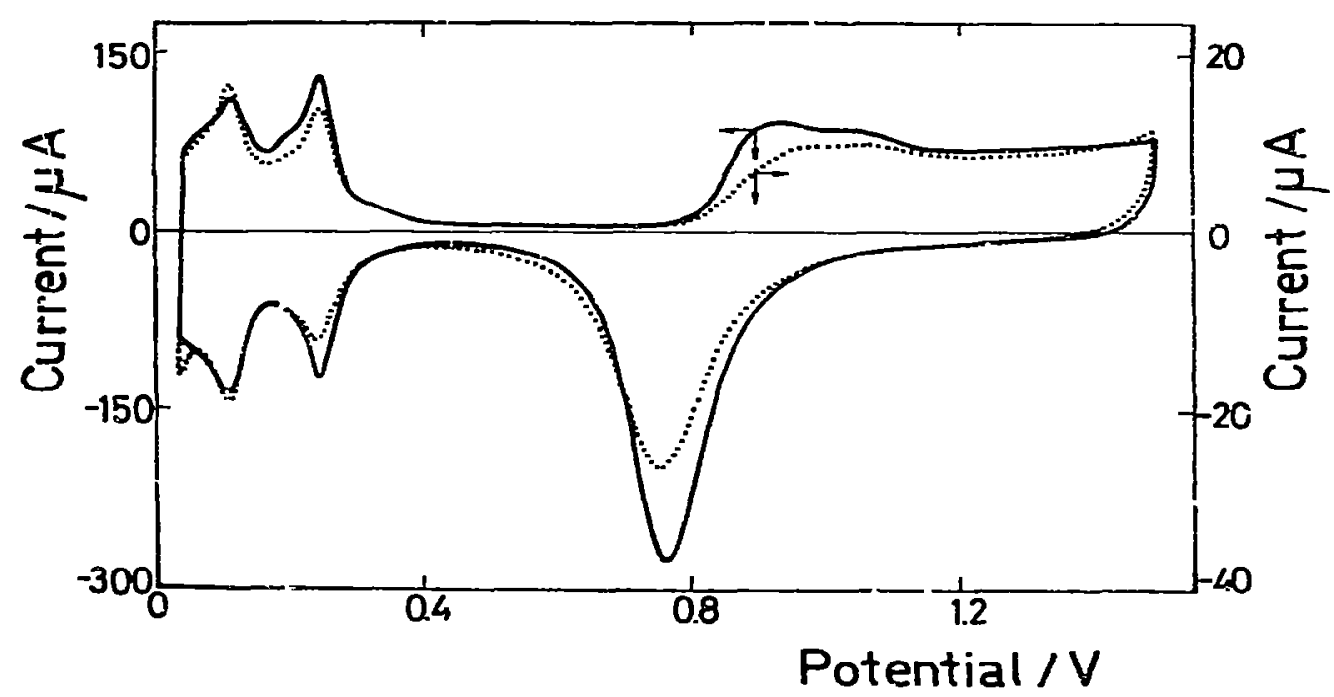

Fig. 2. Stabilized voit.immograms (third cycle) run at $0.1 \mathrm{~V} / \mathrm{s}$ in $1 \mathrm{M} \mathrm{H}_{2} \mathrm{SO}_{4}$ at $25^{2} \mathrm{C}$. (—) After $2 \mathrm{~h}$ of RTPS at $1000 \mathrm{~V} / ;$ between 0.04 and $1.50 \mathrm{~V} ;(\cdots \cdots)$ untreated polycrystalline platinum electrode. 
inhibited. Thus, after $2 \mathrm{~h}$ of RTPS at $2000 \mathrm{~V} / \mathrm{s}$ the increase in the electrode active area furnishes a limiting value of $R$ close to 3 and the voltammogram shape at $v=0.1 \mathrm{~V} / \mathrm{s}$ (Fig. 3) remains stable on further $\mathrm{R}$-PS at the same frequency. But when the electrode is subjected to RTPS at $0.1 \mathrm{~V} / \mathrm{s}$ between 0.04 and $1.50 \mathrm{~V}$ for ca. $30 \mathrm{~min}$, the electroc:ımical response $t \in$ nds to return gradually to that of polycrystalline platinum. The electrochemical response similar to that of the platinum (100) single crystal surface can be recovered by repeating the RTPS at $2000 \mathrm{~V} / \mathrm{s}$ for $1 \mathrm{~h}$.

When the RTPS treatment is carried out at $3000 \mathrm{~V} / \mathrm{s}(f \simeq 1 \mathrm{kHz})$ for $2 \mathrm{~h}$, the electrochemical characteristics of the resulting surface electrode are similar to those described after applying the RTPS at $2000 \mathrm{~V} / \mathrm{s}$. However, at this frequency the platinum surface with a preferred orientation can also be obtained after only several minutes of RTPS without an appreciable increase in the electrode active surface area. When this electrode is subjected to RTPS at $0.1 \mathrm{~V} / \mathrm{s}$ between 0.04 and $1.50 \mathrm{~V}$ for $15 \mathrm{~min}$, surface reconstruction is again obserjed.

The RTPS treatment at $10000 \mathrm{~V} / \mathrm{s}(f=3.42 \mathrm{kHz})$ applied for only a few minutes yields a surface structure whose voltammogram at $0.1 \mathrm{~V} / \mathrm{s}$ approaches closely that of the platinum (100) single crystal surface. Furthermore, the voltammogram shows no increase in the active electrode area (Fig. 4). After $2 \mathrm{~h}$ of RTPS at $0.1 \mathrm{~V} / \mathrm{s}$ between 0.04 and $1.50 \mathrm{~V}$, a very slight reconstruction of the electrode surface and a small increase in the electrode active area are noticed. This suggests that the increase in the electrocle active area can be related to the development of a small fraction of new facets including defects (kinks, steps, etc.).

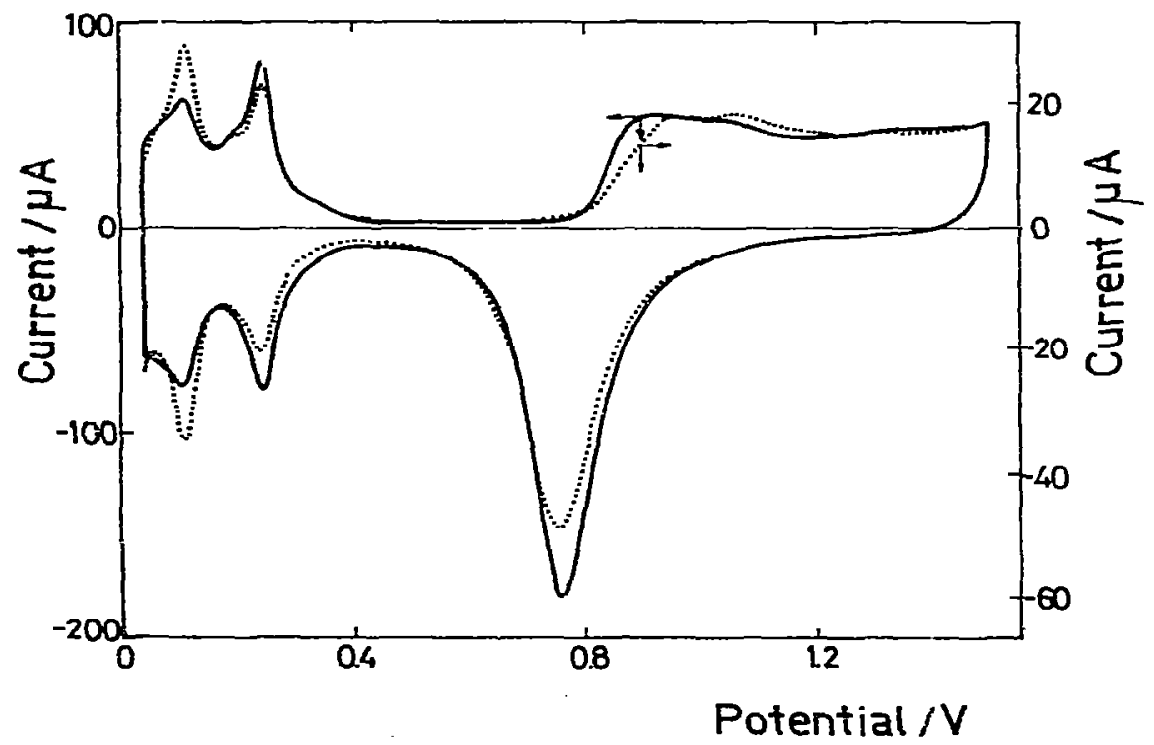

Fig. 3. Stabilized voitammograms (third cycle) run at $0.1 \mathrm{~V} / \mathrm{s}$ in $1 \mathrm{M} \mathrm{H}_{2} \mathrm{SO}_{4}$ at $25^{\circ} \mathrm{C}$. (—-) After $2 \mathrm{~h}$ of RTPS at $2000 \mathrm{~V} / \mathrm{s}$ between 0.04 and $1.50 \mathrm{~V} ;(\cdots \cdots)$ untrited polycrystalline platinum electrode. 


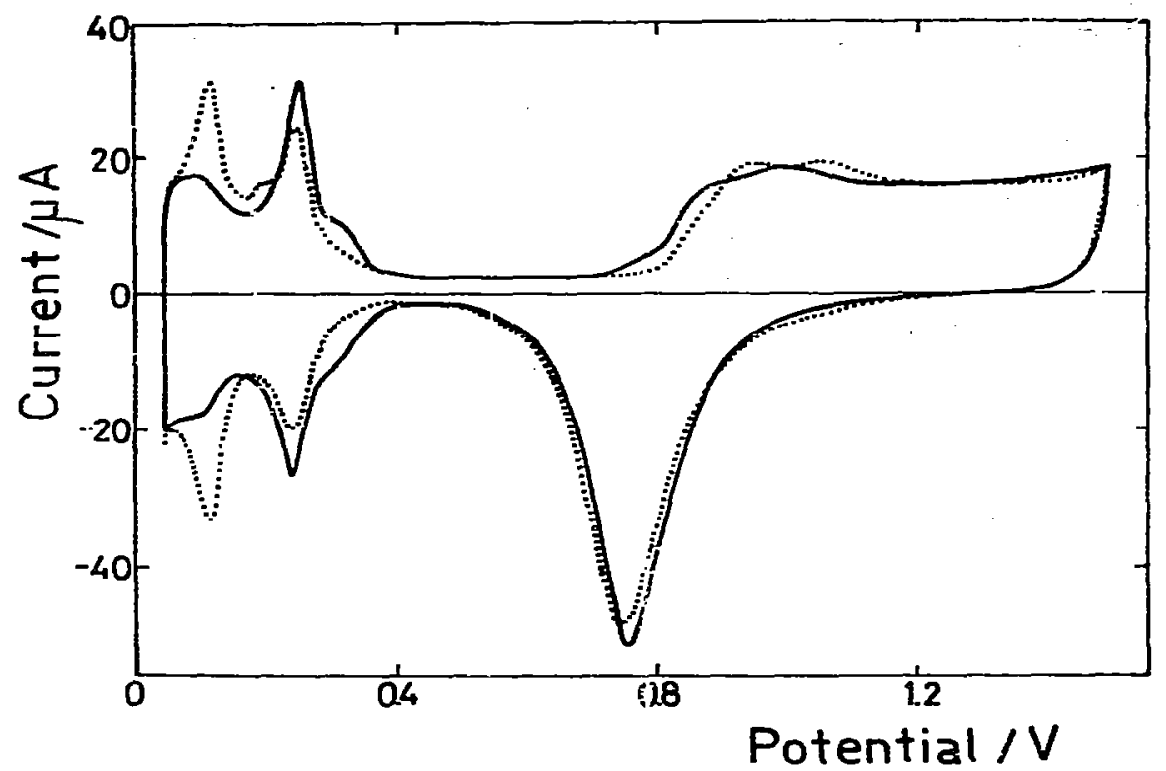

Fig. 4. Stabilized voltammograms (third cycle) run at $0.1 \mathrm{~V} / \mathrm{s}$ in $1 \mathrm{M} \mathrm{H}_{2} \mathrm{SO}_{4}$ at $25^{\circ} \mathrm{C}$. (一-) after 6 min of RTPS at $1000 \mathrm{v} / \mathrm{s}$ between 0.04 and $1.50 \mathrm{~V} ;(\cdots \cdots)$ untreated polycrystalline platinum elecirode.

The platinum surface resulting after RT'PS at $10000 \mathrm{~V} / \mathrm{s}$ for $15 \mathrm{~min}$ shows no change in electrochemical response at $0.1 \mathrm{~V} / \mathrm{s}$ after holding the potential at $2.2 \mathrm{~V}$ for $5 \mathrm{~min}$.

Development of platinum electrode surfaces with a high contribution of (111)-like sites

When the :switching potentials of the RTPS are fixed at $E_{1}=0.40 \mathrm{~V}$ and $E_{u}=1.60 \mathrm{~V}$, i.e. in the O-adatom potential range, after only $5 \mathrm{~s}$ of RTPS at 2000 $\mathrm{V} / \mathrm{s}(f=0.83 \mathrm{kHz})$, the voltammogram run immediately afterwards at $0.1 \mathrm{~V} / \mathrm{s}$ between 0.04 and $1.50 \mathrm{~V}$ (Fig. 5) is much more similar to that of a platinum (111) single crystal surface after it has been cycled a few times through the anodic oxicle region at a relatively low $v$ (e.g. $0.1 \mathrm{~V} / \mathrm{s}$ ) $[2-4,16-18]$ and is also similar to that resulting from a platinum (111) single crystal surface subjected to argon ionic icombardment [19]. Thus, the corresponding conjugated reversible current peaks at $0.11 \mathrm{~V}$, a relative increase in the height of the second broad curient peak associated with the O-electroadsorption, and a shift of the O-electrodesorption current peak towards more negative potential values are observed. In this case, a slight increase in the electrode active area is noticed. But when the potential perturbation at $2000 \mathrm{~V} / \mathrm{s}$ lasts for $30 \mathrm{~s}$, then the voltammogram run immediately afierwards at $0.1 \mathrm{~V} / \mathrm{s}$ between 0.04 and $1.50 \mathrm{~V}$ shows a partial reconstruction of the electrode surface and 


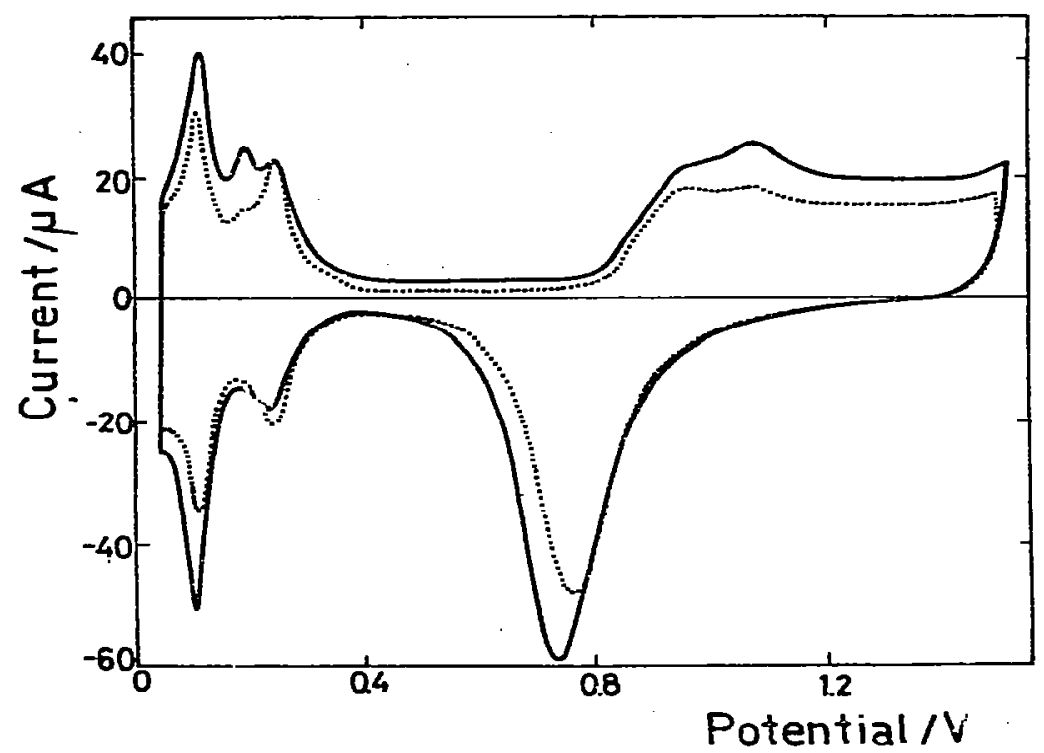

Fig. 5. Stabilized voltammograms (third cycle) run at $0.1 \mathrm{~V} / \mathrm{s}$ in $1 \mathrm{M} \mathrm{H}_{2} \mathrm{SO}_{4}$ at $25^{\circ} \mathrm{C}$. ( - - After $\mathrm{S} \mathrm{s}$ of RTPS at $2000 \mathrm{~V} / \mathrm{s}$ between 0.40 and $1.60 \mathrm{~V} ;(\cdots)$ untreated polycrystalline platinum electrode.

an increase of the electrode active area $(R=3)$. Surface reconstruction is enhanced by further RTPS at $10000 \mathrm{~V} / \mathrm{s}$. In this case, after $15 \mathrm{~s}$ of RTPS the electrode active area increases approximately ten-fold with respect to the initial active area of the polycrystalline platinum electrode.

\section{Influence of electrolyte composition and organic impurities}

The preparation of piatinum electrode surfaces with preferred orientations by application of RTPS at $10000 \mathrm{~V} / \mathrm{s}$ is, in general, independent of the composition of the three acid electrolytes empicyed in the present work (Fig- 6). The minor influence of the electrolyte composition is a reasonable result because at the high frequencies employed the rate of the anion adsorption/desorption process is probably too small to respond to the rapid change of the periodic triangular potential sweep. Nevertheless, it should be mentioned that the voltammetric definition obtained in $\mathrm{H}_{2} \mathrm{SO}_{4}$ and $\mathrm{H}_{3} \mathrm{FO}_{4}$ solutions is better than that observed in $\mathrm{HClO}_{4}$ sclutions.

In contrast, the presence of traces of organic impurities. in solution, which are detecied through the stability of the RTPS voltammogrim at $0.1 \mathrm{~V} / \mathrm{s}$ in the $H$-adaiom potential range, oistructs the development of platinum surfaces with preferred orientations. The effect of organic impurities appears similar to the levelling effect of organic additives in metal electrocrystallization [20]. On the other hard, the preparation of platinum surfaces with preferred orientations depends 


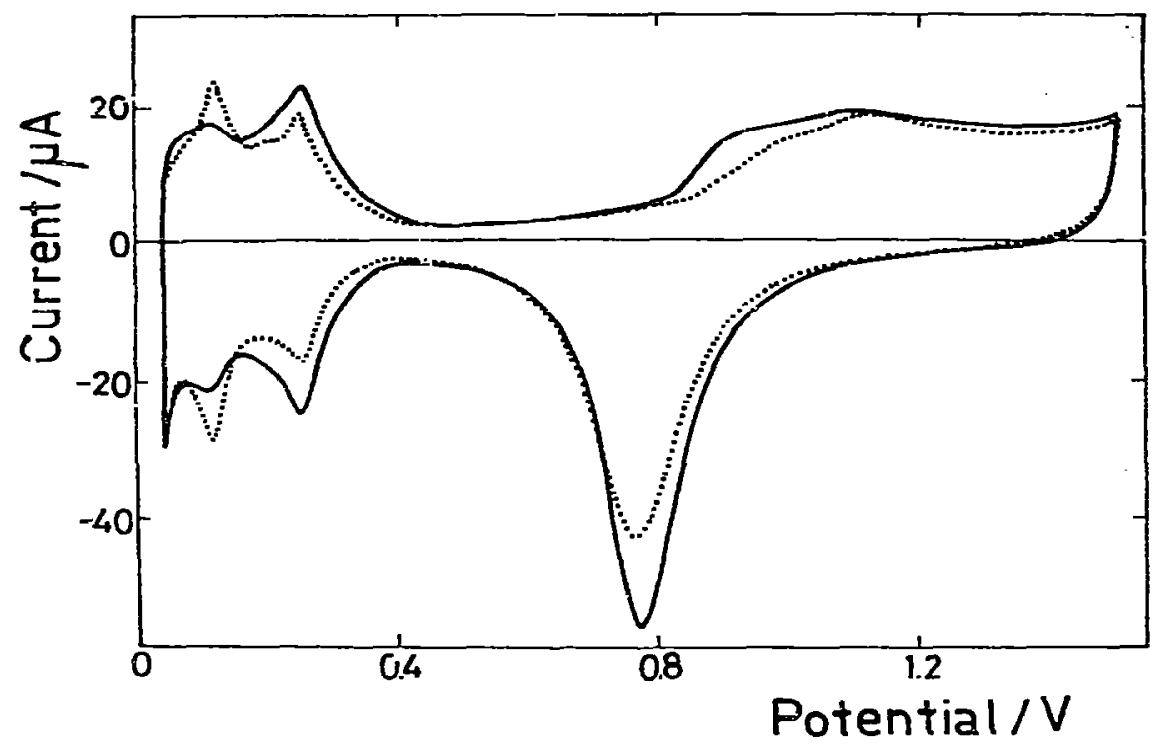

Fig. 6. Stabilized voltammograms (third cycle) run at $0.1 \mathrm{~V} / \mathrm{s}$ in $1 \mathrm{M} \mathrm{H}_{3} \mathrm{PO}_{4}$ at $25^{\circ} \mathrm{C}$. (-—) After 10 min of RTPS at $10000 \mathrm{~V} / \mathrm{s}$ between 0.04 and $1.50 \mathrm{~V} ;(\cdots)$ ) untreated polycrystalline platinum electrode.

likewise on the history of the initial polycrystalline electrode, including the mechanical pretreatment of the metal.

\section{DISCUSSION}

The present results reveal that the application of a relativeiy fast RTPS $(0.034$ $\mathrm{kHz}<f<3.42 \mathrm{kHz}$ ) produces two dirferent effects at the electrode surface, namely, an increase in the electrode active area and the development of a preferred orientation. Apparentiy, the former prevails at a relatively low frequency range and the latter predominates at a relatively high frequency range.

Previous results on noble metal electrcdes [11] and those reported here indicate that the RTPS applied within the potential range of $\mathrm{H}$ - and $\mathrm{O}$-adatom electroadsorption/electrodesorption in acid electrolytes produces different effects accordingly to the $v$ (or $f$ ) employed. Tnus, at low $v$ values, of the order of $0.001-0.1 \mathrm{~V} / \mathrm{s}$, as usually employed in conventional voltammetry, the $\mathrm{H}$ - and $\mathrm{O}$-adatom electroadsorption/electrodesorption processes during the initial potential scanning are accompanied by base metal electrodissolution and metal ion electrodeposition together with sintering [21,22]. The overall effect produces a small change in the electrode active surface area. At an intermediate $v$ range,i.e. in the range $100-1000 \mathrm{~V} / \mathrm{s}$, sintering is no longer an appreciable effect so that the remaining ones, namely, the electrodissolution and the electrodeposition of the base metal during the potential cycling, rentier a considerable increase in the electrode active area. Finally, at a $v$ as high as 
$10000 \mathrm{~V} / \mathrm{s}$ the prevailing effect is the development of a preferred orientation at the surface, with a negligible influence on the electrode active area.

The present results show that the frequency threshold for producing a preferred orientation at the platinum surface is ca. $0.5 \mathrm{kHz}$. This figure coincides with that of the repetitive square wave potential sweep which was able to produce a preferential orientation of grains at polycrystalline platinum electrodes, and its reciprocal was associated with the half-life time of the adsorbed $\mathrm{OH}$ species on platinum $[9,10]$. Therefore, it is reasonable to relate the metal surface modification to the occurrence of the initial revarsible underpotential electrooxidation of water on platinum where the Pt(Ori) ad species is formed [9]. When the probable rate constants of the various stages involved in the O-electroadsorption are considered [23], it is concluded that at frequencies greater than $0.5 \mathrm{kHz}$, either (O)Pt formation or ageing effects of the $O$-adsorbed monolayer can be ignored. The latter processes are relevant when relatively slow repetitive triangular potential sweeps are applied to platinum electrodes in acid electrolyte into the region of oxide formation. In this case, when single crystal electrodes are used, it results in oriented but atomically stepped surfaces [24].

The explanation of the development of surfaces with a preferred orientation can be thought of in terms of a dynamic lattice model, where the surface atoms of platinum are oscillating principally in a direction perpendicular to the electrode surface according to the potentiodynamic induced water electrooxidation reaction. This causes a periodic separation of metal atoms in the first lattice planes which exceeds the bond length of any crystal structure yielding a jelly-like metal atom lattice which subsequently is able to accommodate preferred orientations. According to the present results, the type of orientation apparently depends whether the corresponding $E_{1}$ switching potential lies in $\mathrm{H}$-adatom potential range or not. In the former case, the presence of $\mathrm{H}$-adatoms interacting with the metal lattice probably facilitares the formation of a surface structure with a high contribution of (100)-like sites, while in the absence of $\mathrm{H}$-adatoms the densest structure, namely, that corresponding to the predominance of (111)-like sites, is formed. The participation of $\mathrm{H}$-adatoms in defining the resulting preferred orientation can be equally related to the structural characteristics of water in each case. From the physical standpoint, the effect of RTPS at frequencies in the range $0.5 \mathrm{kHz}<f<5 \mathrm{kHz}$ resembles that of electron bombardment of the crystal surface with the appearance of seft surface phonons [7,8]. However, at present it is speculative to advance a more complete mechanistic interpretation of the metal surface monoorientation. Further results which are being obtained with other systems will serve for this purpose in the near future. This does not impoverish the practical importance of the technique developed in the present paper for managing platinum electrode surfaces on a miore sound structural basis.

\section{ACKNOWLEDGEMENTS}

INIFTA is sponsored by the Consejo Nacional de Investigaciones Cientificas y Técnicas, the Universidad Nacional de La Plata, and the Comision de Investigaciones Cientıficas (Provincia de Buenos Aires). 


\section{REFERENCES}

1 L.V. Azároff, Elem:ents of X-Ray Crystallography, McGr.3w-Hill, New York, 1968.

2 P.N. Ross, jr., J. E' cctroanal. Chem., $7 \in$ (1977) 139.

3 A.T. Hubbard, R.M. Ishikawa and J. Katekaru, J. Electroanal. Chem., 86 (1978) 289.

4 J. Clavilier, R. Fau:e, G. Guinet and R. Durand, J. Electroanal. Chem., 107 (1980) 205.

5 J.P. Ganon, N.V. Huong and J. Clavilier, Surf. Sci., 79 (1979) 245.

6 J. Lecoeur, C. Sella. L. Tertian and A. Hamelin, C.R. Ac.3d. Sci., Paris, Ser. C, 280 (1975) 247.

7 D. Castiel and L. Dobrzynski, Surf. Sci., 63 (1977) 21.

8 J.G. Sanz and G. Armzno. Surr. Sci., 118 (1982) 291.

9 A.C. Chialvo, W.E. Triaca and A.I. Arvia, J. Electroanal. Chem., 146 (1983) 93.

10 A.C. Chialvo, W.E Triaca and A.J. Arvia, J. Electroanal. Chem., 171 (1984) 303.

11 R. Cerviño, W.E. Triaca and A.J. Arvia. J. Electrochem. Soc., in press.

12 R. Woods in A.J. Bard (Ed.), Electroanalytical Chemistry. Vol. 9, Edward Arnold, London. 1977.

13 G. Bèlanger and A.K. Vijh in A.J. Vijh (Ed.), Oxides and Oxide Films, Vol 5. Marcel Dekker, New York, 1977.

14 F.G. Will, J. Electrochem. Soc., 112 (1965) 451.

15 E. Yeager, W.E. O'Grady, M.Y.C. Woo and P. Hagans, J. Electrochem. Soc., 125 (1978) 125.

16 X. Yamamoto, D.M. Kolb. R. Kotz and G. Lehmpfuhl, J. Electroanal. Chem., 96 (1979) 233.

17 P.N. Ross, Jr., Surf. Sci., 1022 (1981) 463.

18 F.E. Woodward, C.L. Scortichini and C.N. Reilley, J. Electroanal. Clıem., 151 (1983) 109.

19 D. Aberdam, C. Corotte, D. Dufayard, R. Durand, R. Faure and G. Guinet in D.A. Degras and $M$. Costa (Eds.), Proceedings of the Fourth International Conference on Solid Surfaces, Cannes, Vol. I, p. 622, Suppl. io Le Vide, Les Couches Minces, No. 201 (1980).

20 C.J. Raub in J.O'M. Bockris, B.E. Conway, E. Yeager and R.E. White (Eds.), Comprehensive Treatise of Electrochemistry, Vol. 2, Plenum Press, New York, 1981.

21 D.A.J. Rand and R. Woods, J. Electroanal. Chem., 35 (1972) 209.

22 A.E. Bolzan, M.E. Martins and A.J. Arvia, J. Electroanal. Chem., 157 (1983) 335.

23 J.O. Zerbino, N.R. de Tacconi, A.J. Calandra and A.J. Arvia, J. Eleztrochem. Soc., 124 (1977) 475.

24 F.T. Wagner and P.N. Ross, Jr., J. Electroanal. Chem., 150 (1983) 141. 